\title{
VALUE FOCUSED THINKING: AN APPROACH TO STRUCTURE COMPANY VALUES FOR ASSET RISK MANAGEMENT
}

\author{
Van Der Lei TE ${ }^{a}$ and Ligtvoet $\mathrm{A}^{\mathrm{a}}$ \\ ${ }^{a}$ Energy \& Industry Section, Faculty of Technology Policy and Management, Delft University of \\ Technology, Jaffalaan 5, Delft, 2628 BX, Netherlands.
}

For public and semi public organizations the use of risk assessment matrices is becoming a standard approach for asset management decisions. The risk matrix allows companies to assess the chance and effects of different risks with respect to proposed investment decisions. When the values in the risk matrix reflect the company values, the risk matrix allows for investment decisions to be made in line with these values and even for further strategic decision making. In this paper we describe how a hierarchy of values can be used to uncover the core values of a company. These values are often shared by the people in a company and are institutionalized in core documents, like the strategic vision or annual reports. We describe an approach in which we used Value Focused Thinking [1] for the systematic elicitation of company values to determine the aggregation level of the values represented in the asset risk matrix of the Port Authority of Rotterdam.

\section{INTRODUCTION}

Many public and semi public organizations in the Netherlands are developing their risk based asset management approaches. For risk based asset management risk assessment matrices are used as a decision support tool. The risk matrix allows companies to assess different investment decisions.

A risk assessment matrix states the chance that an event will occur and the effect of the event. The resulting risk is the amount of harm that is incurred for the given event. There are many types of risk assessment matrices that follow this line of reasoning. Differences lie in the scales that are used for the likelihood of the event, effect of the event, and severity of the risk. Most often risk assessment matrices use a single effect scale describing the effects. The risk assessment matrix that was developed in the project is a risk matrix with multiple values with corresponding effects scales. This set up of the risk matrix allows for decision making with respect to multiple values.

The values in the risk matrix are a reflection of the core values of the organization that uses the matrix. Many large companies use this type of risk matrices in their daily practice, e.g. Shell. Public and semi public asset management organizations differ from other types of companies as their assets are most often located in the public domain, and may also be used by the public. These companies are in need of tools to deal with large risks and uncertainties [e.g. 2, 3], also the values of these companies differ from private companies that tend to have a strong focus on shareholder value. In the Netherlands, however, public and semi public organizations have been introducing this type of multi value risk based asset management approach. While there is sufficient literature on the use and misuse of risk assessment matrices [e.g. 4, 5], an approach for the elicitation of the values for the risk assessment matrix is not described [6]. In this paper we describe how we used a three-step approach to elicit the company values of the Port Authority of Rotterdam (PoR). The PoR manages a wide range of different assets: roads, railroads, public spaces \& greenery, buildings, quays, and the waterways (in particular the depth of these waterways). In our approach we used Value Focused Thinking [e.g. 1] combined with document analysis and interviews to elicit the values for the risk assessment matrix of the company involved.

The PoR has a vision to become a global hub and Europe's industrial cluster and wants to mature in its asset management practices by better embedding the asset management philosophy into the organization. This means additional effort regarding the optimization of business processes across different levels of the company. A seamless integrated process of asset management from strategic to operational level can be seen as a high level of "maturity" of the organization [7]. The PoR vision of world class asset management for the company is aimed at this high level of maturity in the business. 
Risk management has been identified as a central pillar of asset management that is not sufficiently supported in the current business.

\section{ANALYSIS OF VALUES}

Value elicitation differs with respect to the purpose of the elicitation and the scientific field. Fischhoff [8] shows that different research paradigms have different assumptions with respect to values. He describes three different paradigms. The first paradigm assumes that people know what they want and is called the philosophy of articulated values. The second paradigm assumes that people have stable perspectives but that they are incoherent - the Philosophy of partial perspectives. The third paradigm assumes that people lack articulated values on specific topics but have pertinent basic values that are stable. This final paradigm is called the philosophy of basic values. Value elicitation of stable values Fischhoff [8] argues differs from value elicitation in the two other paradigms. The risk assessment matrix assumes that the values are (relatively) stable and that choices can be made with respect to these values. This corresponds with the third paradigm.

The matrices that are in use in the energy sector in the Netherlands today are adaptations of the risk matrix approach of Shell that had the values people, safety, environment and reputation. The reason to adopt the matrix was that a tried and tested tool does not need to be changed substantially. Since the original implementation of the risk matrix, over the years, most companies have altered the values in their matrices. For example, for one organization the value "sustainability" (in terms of an ecological footprint) was added, while for another the value "legality" was dropped arguing that all operations should comply with legal requirements. Overall the values in the matrices of the sector have remained relatively stable.

Values arise from a process in which shared values are formed. These values are expressed, communicated, and recorded in documents. Reasoning from this perspective of shared value formation, business values are not thought to be decided, but they are the result of individual thought processes and communication of the employees (and thus can be elicited by researchers). Of course, some individuals, such as a CEO, can have more influence on the values of an organization [9].

When values are recognized by the organization they are recorded and most often this is done by management. When values are seen as formal objectives, this is a further step in translating values into business practice. These type of values are periodically established in strategic documents, which in turn influence the thinking about values.

To elicit corporate values official documents can be studied and its people interviewed. As for documents a translation takes place into text, and the documents are merely an official representation of the values actually underwritten by the employees. These official documents are important, as they are formalized and institutionalized. To illustrate, most companies today have mission statements and corporate strategic documents that reflect their values [10]. Depending on the type of strategic document (e.g. annual reports, operational plans, or visionary statements) the values are expressed in different ways. Most often the values represented in these documents are not centrally collected and systematically structured.

In order to gain an understanding of the corporate values, careful argumentative analysis is needed to uncover values from text. A text may read as follows:

"We continuously improve our company to become the most secure, efficient and sustainable in the world. For our customers we create value by developing value chains, networks and clusters, both in Europe and in emerging markets worldwide. Our company is an entrepreneur and developer of worldclass partnerships for customers in the petrochemical, energy, and transportation and logistics sector. In this way we also strengthen the competitiveness of the Netherlands."

Keeny has provided a method that allows for the structuring of values. The method of Keeny falls into the paradigm of stable values as he describes values as principals used for evaluation [1, p. 6]. Values may be structured using a hierarchy of values or objectives hierarchy (See Figure 4) [1, 11, 12, 13]. At the top of the hierarchy the central value is provided and this value is defined by the lower values in the hierarchy. The lowest level values may be operationalized into Key Performance Indicators, making the values measurable and/or quantifiable. The principle of value trees for a company is simple: the top is formed by the most important value in the mission statement of the organization. The layer below contains the values that define the mission. These values can be further specific by lower level values as needed. 


\section{APPROACH}

Setting up a risk matrix based on corporate values is not a standard procedure. Public and semi public organizations in the Netherlands that we interviewed have approached the construction of the matrix very differently. Some choose to organize company-wide discussion sessions to set up the values in the matrix, others frame the values in a limited circle - like the executive team. A structured approach like the one presented in this paper was not used.

For this research project we developed a three staged approach in order to elicit the corporate values of the Port Authority of Rotterdam (See Figure 3).

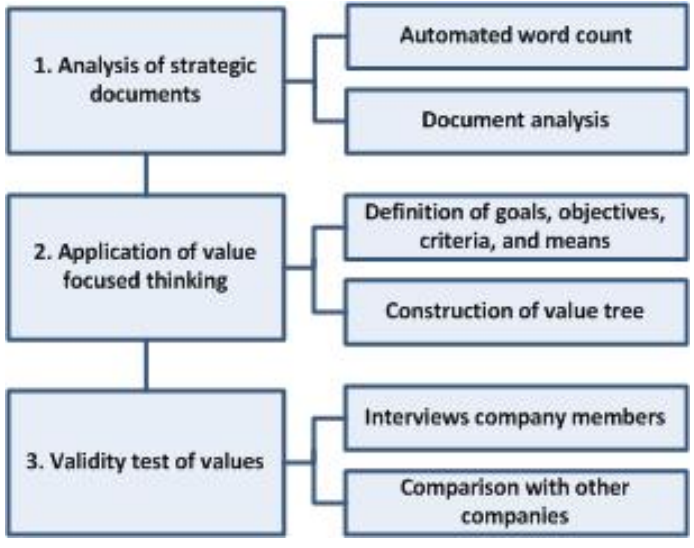

Figure 3: Adopted value elicitation approach

Analysis of strategic documents: In this stage the corporate strategic documents were analyzed for values, objectives, criteria and means. This was done by the researchers. To supplement the document analysis, an automated word count of multiple strategic documents was done to investigate what type of nouns were used most often in the strategic documents and whether these nouns represent values (e.g. when in a strategic implementation plan the word "environment" is mentioned most, we assume that this is an important focal point).

Application of value focused thinking: In this stage the collected goals, objectives, and criteria were clustered and used for the construction of the value tree. The clustering and the construction of the value tree was done by the researchers. In addition, two strategic documents were translated separately into value trees. Based on the analysis of the company documents, a synthesis tree was built that combined elements of both trees.

Validity test of values: Validity was measured as: the extend to which the uncovered values were shared by the company. In order to receive this feedback regarding the elicited values, the tree was used in eleven interviews with company employees. Nine heads of department were interviewed, a program manager and an advisor at corporate strategy level were asked to check the values and assumptions that were made on lower levels with respect to the constructed trees.

\section{RESULTS}

For the Port Authority of Rotterdam three value trees were constructed. The first two value trees were based on two important strategic documents that were assumed to be known throughout the whole company. The first document was a medium term document, a 5 year - Organizational Plan, with key performance indicators but also broader goals such as internationalization and cooperation. The second document was a longer-term document, a 20 year Port Vision, a document with an integrated vision for the region that goes beyond the borders of control of the PoR as it also encompasses regional development. The translation of the values in these core documents into value trees allowed us to explain the concept of value trees, which was new to the organization. The third tree contained the values we collected from a larger sample of documents using the above-explained approach (see Figure 4). This value tree was larger and contained more levels than the first and second tree that were based solely on the corporate documents.

As a result of the second step in the process we arrived at five corporate values that were further subdivided into lower level values. In order to be a global hub and Europe's industrial cluster, the following values were defined:

Safety: Safety was generally recognized as an important value. In all documents various aspects such as environmental safety (emissions and industrial accidents), nautical safety, structural safety (like collapsing structures), and road accidents were mentioned. Being a maritime organization, the documents mainly focused on nautical safety. However, we assumed (and were confirmed in our assumption) that health risks of people both inside and outside the company (number of injuries and / or deaths) was a general concern, not bound to specific modes of transportation as was external safety (which is safety to people and organizations outside the company). 
Environmental Sustainability: encompasses environmental impacts (emissions, discharges, ...) and could be seen as another word for "clean". Sustainability is to be achieved both in the company's own operations, in related transport activities, as well as the activities of its clients. The strategic documents as well as some insights delivered by the risk department clearly indicated that reducing emissions, and decreasing the use of raw materials and energy as the focus of sustainability. However, sustainability appeared to be a difficult concept as it meant different things to different people: some of the asset managers concerned with structures also called sustainability the longevity of their assets. Although assets of higher quality generally lead to less time and energy spent on maintenance and replacement, we eventually moved the longevity aspect to societal value creation.

Accessibility: this includes turn-around time of ships and accessibility via roads and rails. In short, this value is about the flow of goods. At first the synthesis tree read efficiency, as efficiency was recognized in the business. The debate was whether this was the best word: efficiency is nothing more than a goal at an acceptable cost. Access is ultimately what was meant by efficiency: the four modalities shipping, rail, road and pipelines need to have sufficient capacity for transport to and from clients, and these modalities need to have sufficient capacity and need to be available as much as possible.

Reputation: in this context means a combination of aesthetics and a positive image among (potential) customers, shareholders and the press. More specifically the organization wants to be known and active as an entrepreneurial developer. Reputation provided most debate as some of our interviewees argued that reputation is the result of a job done well. Furthermore, the term did not appear in the strategic documents we analysed. However, the Board's reasoning is that reputation is a separate point of attention: it ensures the "license to operate" and especially the "license to grow".

Creating (societal) value: includes not only generating sufficient funds for the organization itself for continued operation (like return on investment, profitability), but also a broader goal to create value for clients, the surrounding region, and other stakeholders. Ultimately, this value is expressed in Euros.

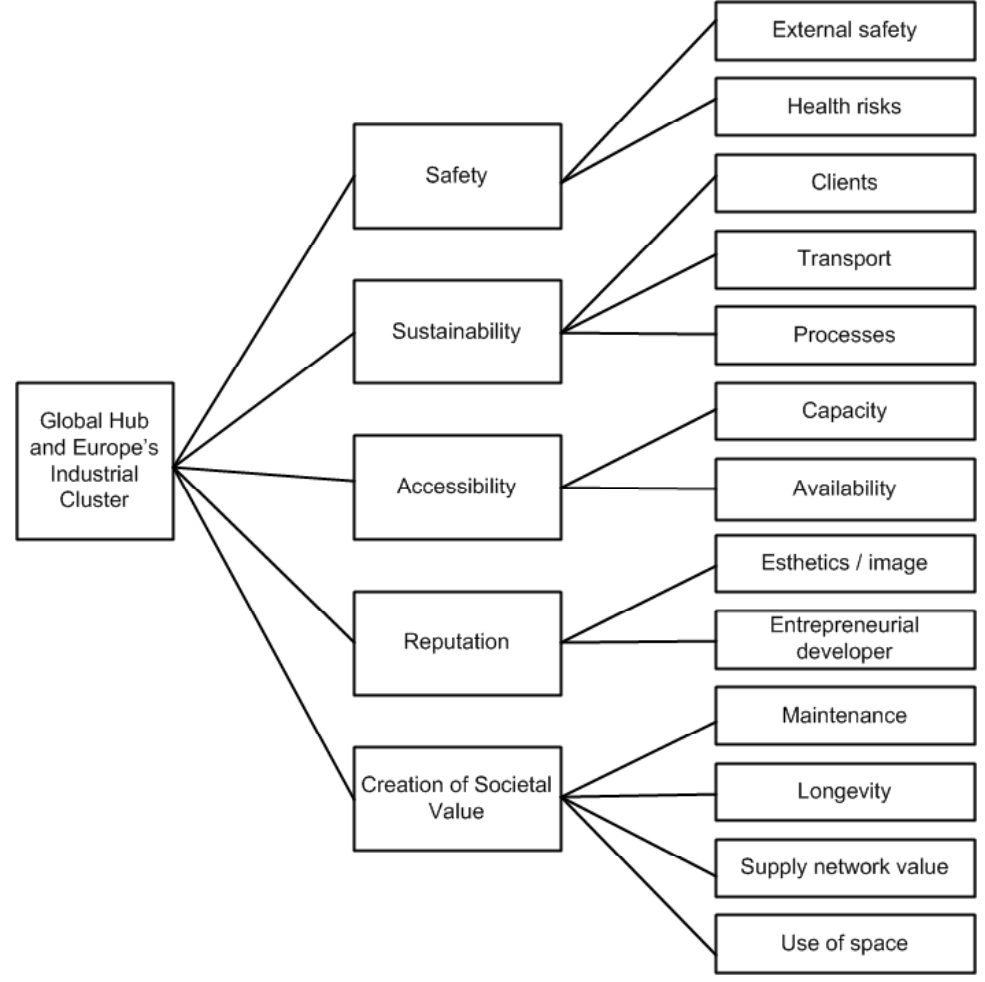

Figure 4: Constructed Value Tree
When we made the translation from the five values to the risk assessment matrix (not discussed in this paper), the less lofty term "finances" was chosen, as this was also widely recognized. The lower level goals related to asset management were cost-effective maintenance and longevity of assets. Other concerns are facilitating the supply networks and the use of space.

In arriving at these five values, some decisions had to be made as to what should be considered a main value and what a supporting value: a need-to-have versus a nice-to-have. The medium term strategic document, for example, mentioned the ambition to expand beyond the borders of the Netherlands. Although this was a prominent item in the document, we argued that international presence is not a core value of the company. In other words: the organization would still be itself without the international presence, whereas loosing safety or sustainability as a value would constitute a major change for the entire organization. Eventually all interviewees agreed on the values. Most discussion took place regarding the lowest level values. 


\section{DISCUSSION AND CONCLUSION}

In large organizations that are not strictly hierarchically controlled, similar activities take place at different departments. This may be because the organization is "ripe" for its next organizational changes. Following a meeting with the risk department it turned out that the higher corporate levels made use of five values unknown to the asset management department, these were: Safety, Assets / Finance, Environment, Reputation (public, stakeholders / customers) and Core Business. The similarity to our identified values was very large, with the only exception that what the risk department had called "Core business", we had labeled "accessibility". The shared focus on risk was seen as an opportunity for further risk (based asset management) thinking throughout the whole organization.

Although this value discovery exercise was set up with the aim of constructing a risk matrix, knowing ones values (as an organization) has several purposes. The values provide a guideline for many business decisions: they allow for prioritizing projects, for investments decisions, and act as guidelines for annual reports. Risk assessment is becoming an integral part of total company practice.

In the Netherlands where the semi public energy network companies are most advanced in their risk based asset management practices we see this trend of integration. Three of these companies we interviewed with respect to their risk based asset management practices. All organizations visited, used their corporate values in their risk assessment matrices. One of the companies is very advanced with respect to risk based management as the entire company uses the same values for decisions making the strategic down to the operational level the same risk matrix is used. In the second interviewed company the risk matrix was used solely in the department of asset management; but the tools used at the risk management department and the department of asset management communicate with each other (there are schemes in which the two systems are coupled together). Finally, at the third energy company, the part of the company responsible for asset management uses a risk matrix based on the company values, while the parent company uses a different approach. However in this company there is an active discussion on what level the risks should be established.

Such a scenario is also conceivable for the Port of Rotterdam: the risk matrix developed for the departments involved in becoming world class in asset management does not have to be rolled out company wide immediately. A transition phase with multiple risk assessment tools in place is possible. However, as one of the objectives of asset management is the proper integration of asset life cycle management throughout the organization it is advisable to aim for companywide integration of the risk assessment tool used.

Finally, in practice, it is difficult to draw up a consistent value tree. The requirement of a good tree is that each value is defined by more than one underlying value and that it is comprehensive (no lacking items) and non-overlapping (no double items). The question whether a value is stated at the appropriate level in the hierarchy is a matter of logic, but its importance is also subject to the evaluation of the actors from the organization. As such, there is no "right" value tree.

Although value trees can be created using a bottom up process, or by using document analysis with selected interviews as we did, the corporate values that are selected to for risk based asset management should be supported by the board of directors. Then only does the tree turn into the "right" tree. It should be noted that such a tree will require regular updates due to 1) new insights by the service providers and asset managers and 2) new strategic insights and directions at the asset owner level.

\section{REFERENCES}

1. Keeny, R.L. Value Focused Thinking, a path to creative decision making, $1992 .$.

2. Marshall, H. E. Techniques for treating uncertainty and risk in the economic evaluation of building investments, U.S. Department of Commerce, 1988

3. Phillips, S.; Martin, J.; Dainty, A. \& Price, A. Uncertainty in best value decision making, Journal of Financial Management of Property and Construction, 2007, 12, 63-72

4. Cox Jr. , L.A., What's Wrong with Risk Matrices? Risk analysis, 2008, 28(2)

5. Wijna, Ype, Asset risk management: issues in the design of a risk matrix, 2010.

6. Mills, G. R.; Austin, S. A.; Thomson, D. S. \& Devine-Wright, H. Applying a universal content and structure of values in construction management, Journal of Business Ethics, 2009, 90, 473-501

7. Volker, Leentje; van der Lei, Telli; Ligtvoet, Andreas, Developing a maturity model for infrastructural asset management systems, Conference on applied infrastructure research, Berlin, 7-8 October 2011

8. Fischhoff, B. (1991) Value elicitation: Is there anything in there? American Psychologist, Vol 46(8) 
9. Collins, J. C. \& Porras, J. I. Building your company's vision, Harvard Business Review, 1996, SeptemberOctober, 96501

10. David, F. R. How Companies Define Their Mission, Long Range Planning, 1989, 22, 90-97

11. Keeney, R. L. Building models of values, European Journal of Operational Research, 1988, 37, 149-157

12. Keeney, R. L. Using Values in Operations Research, Operations Research, 1994, 42, 793-813

13. Kirkwood, C. W. 1997. Strategic Decision Making: Multiobjective Decision Analysis with Spreadsheets. Pacific Grove, CA: Duxbury Press.

\section{ACKNOWLEDGEMENTS}

This work was for the project "Asset Life Cycle Management for the Port Authority of Rotterdam" and was supported by the Next Generation Infrastructure Foundation. 